\title{
Influence of Core Thickness and Boundary Condition on the Modal Characteristics of Composite Structure with Metallic Damping Core
}

\author{
Fuhao Peng, Yiwan Wu (D), Hongbai Bai, Yichuan Shao, and Zhiqiang Qin \\ Engineering Research Center for Metal Rubber, School of Mechanical Engineering and Automation, Fuzhou University, \\ Fuzhou 350116, China \\ Correspondence should be addressed to Yiwan Wu; wuyiwan@fzu.edu.cn
}

Received 1 January 2020; Revised 17 July 2020; Accepted 26 August 2020; Published 19 September 2020

Academic Editor: Nuno M. Maia

Copyright (c) 2020 Fuhao Peng et al. This is an open access article distributed under the Creative Commons Attribution License, which permits unrestricted use, distribution, and reproduction in any medium, provided the original work is properly cited.

To reduce the vibration of the plate-like structure under different boundary conditions, an all-metal damping composite structure was proposed, and its damping layer was entangled metallic wire material (EMWM). A series of quasi-static compression tests were carried out to investigate the damping property of the EMWM layer. A modal test system was set up to evaluate whether the EMWM could dissipate vibration energy. The evaluation results showed that the displacement deviation between the baseplate and constraining plate of the structure was large enough and the EMWM could dissipate vibration energy in the form of friction. The modal characteristics of the composite structure with different core thicknesses under different boundary conditions were researched in this paper by experimental modal tests. The outcomes showed that the damping ratio of the structure would be significantly improved by adding EMWM and constraining plate. The larger the thickness of the core thickness is, the larger the damping ratio and vibration reduction performance of the composite structure are. This paper provides a new technical way for the damping design of high temperature plate structure.

\section{Introduction}

Vibration and noise are ubiquitous in the fields of aviation, automobiles, ships, and buildings. These vibrations and noise will accelerate the fatigue damage of the structure, shorten the service life of the equipment, affect the comfort of the working and living environment, and even harm the health of the human body. Research on reducing vibration and noise by strengthening structural stiffness or improving structural energy dissipation performance has been done by many researchers.

Viscoelastic materials are widely used to mitigate the vibration in the form of constrained layer dampers (CLD) or free layer dampers (FLD). It has been proved that CLD is more effective than FLD for a given added weight [1]. Polymer-based damping material is one of the effective damping cores for reducing vibration [2]. Numerous researches have been motivated to investigate the damping mechanism and characteristics of sandwich structure with different core materials [3-9].

Entangled metallic wire material (EMWM) is a porous material with high damping properties. EMWM is made of various entangled metallic wire helixes. The damping mechanism of the EMWM is that when the EMWM is excited by external vibration, the internal wire helixes will slide, fractionate, and extrude, and then the vibration energy will be dissipated and converted into frictional heat energy. The special manufacturing process makes the EMWM have better special mechanical properties than other porous materials, such as high damping, high elasticity, environmental adaptability (high- and low-temperature resistant, antiaging, and nonvolatile), and high sound absorption coefficient. Therefore, EMWM has been extensively investigated and applied [10-24].

Plate structure is a common structural shape. The sandwich structure is a kind of plate structure that has been 
widely studied for its special physical and mechanical properties (damping characteristic, piezoelectric characteristic) $[25,26]$. As shown in Figure 1, to reduce the vibration of the baseplate, the baseplate is bound with a viscoelastic material layer and a constraining layer by an adhesive. The damping mechanism of this structure is shear energy dissipation of the viscoelastic material layer.

The mechanical and damping properties of the EMWM are affected by many factors, such as geometry and density. In previous researches, the EMWM are often processed into cylinders, squares, and so forth to reduce the vibration of the equipment. For vibration reduction of plate-like structure, the EMWM should be processed into a plate and bonded/ mounted with the baseplate.

There have been many research results on the simulation, calculation, and experimental analysis of sandwich structure [27, 28]. However, studies of EMWM as damping layer are very few in literature. $\mathrm{Wu}$ et al. and Xiao et al. carried out studies on the application of plate-like EMWM to reduce the vibration of bellows and pipelines [24, 29]. Their results show that plate metal rubber has good damping properties. Therefore, this paper will explore the application of plate metal rubber in the damping design of plate structures. In the fields of industry, aviation, and navigation, equipment base is used for supporting equipment and is composed of several plates. The base is a key link of the vibration transmission path from equipment to the foundation/fuselage/hull. This paper will conduct the following researches: first, the plates with different boundary conditions will be decomposed from a simplified foundation, and a new composite structure with EMWM core will be proposed; second, a modal test system will be set up; third, the damping mechanism of the new composite structure will be investigated; fourth, the influence of core thickness and boundary condition on modal characteristics of the composite structure with EMWM layer will be researched.

Figure 2 shows the schematic diagram and physical picture of an equipment base. The equipment base is made up of several plates (a face plate, connection plates, web plates, and brackets) welded in the form of seam welding. The degree of freedom of the welded edge of the plate is limited, and the welded edge can be regarded as a fixed connection. Therefore, the base can be decomposed into quadrilateral plates with different boundary conditions. These boundary conditions can be summarized as C-C-C-C (four ends clamped), C-C-C-F (three ends clamped), and C-C-F-F (two ends clamped).

\section{Entangled Metallic Wire Material}

The EMWM is made of 304 (06Cr19Ni10) stainless steel wires. The manufacture of the EMWM is referring to [30]. The diameter of the 304 wires is $0.3 \mathrm{~mm}$, the diameter of the wire helix is $3.5 \mathrm{~mm}$, and the helix angle is $60^{\circ}$. The first purpose of this paper is focused on the effect of core thickness on the dynamic properties of the composite structure, so three batches of EMWM layer with different thicknesses $(4 \mathrm{~mm}, 6 \mathrm{~mm}$, and $8 \mathrm{~mm})$ are manufactured.
Each batch is composed of 5 specimens. Table 1 shows the parameters of the EMWM specimens.

Figure 3 shows the manufactured EMWM specimen and its SEM image. It can be seen from the SEM image that the EMWM specimen can be divided into multisegment curved beams in contact points. The pore structure inside of the EMWM is determined by the contact points of those curved beams. The mechanical properties of the EMWM are determined by the mechanical properties and contact status of these curved beams [16]. When the EMWM is subjected to external loads, sliding friction will occur in the contact points, thus dissipating vibration energy.

2.1. Composite Structure with EMWM Layer. The experimental model proposed in this paper is shown in Figure 4, which is similar to the common sandwich (Figure 1). But the rivet/bolt is used to connect the damping layer and the constraining plate. The EMWM damping layer is relatively slidable between the baseplate and the constraining plate, and the energy dissipation mechanism of the two structures will be different. Figure 4 is the sketch of the composite structure with EMWM layer. For reducing the vibration of the baseplate, an EMWM layer and a constraining plate are mounted with the baseplate by rivets or bolts. The precompression of the EMWM layer is guaranteed by the limit blocks.

When the EMWM is deformed in the micron scale, the internal wire helixes of EMWM will slip and lead to energy dissipation [30]. The adhesive shown in Figure 1 cannot be used for the bonding of EMWM. The reason is that the adhesive may filter into the EMWM, and the internal metallic wire helixes may be bonded at the contact points. Therefore, the adhesive will cause the wire helixes near the surface of the EMWM to be unable to dissipate energy in the form of friction.

The damping mechanism of the composite structure with EMWM layer is as follows: when the baseplate is subjected to external excitation, the displacement response of the baseplate and the constraining plate will be generated, respectively, and the deviation of displacement response between the baseplate and the constraining plate will change the deformation of EMWM; then the vibration energy will be dissipated by friction.

The second purpose of this paper is focused on the effect of the boundary condition on the dynamic properties of the composite structure. Therefore, different boundary conditions are applied to the same composite structure, as shown in Figure 5. The material of the baseplate, constraining layer, and limit blocks is 45 steel. The sizes of the baseplate in the damping composite area are $150 \times 150 \times 8 \mathrm{~mm}^{3}$. The dimensions of the constraining layer are $150 \times 150 \times 3 \mathrm{~mm}^{3}$. The limit block has an inner diameter of $6.2 \mathrm{~mm}$, an outer diameter of $10 \mathrm{~mm}$, and three different thicknesses $(2 \mathrm{~mm}$, $4 \mathrm{~mm}$, and $6 \mathrm{~mm}$ ). Therefore, the same precompression of the EMWM is $2 \mathrm{~mm}$. To obtain the vibration and damping characteristics of the composite structure with EMWM layer, 12 measurement points (points D1 D12) are arranged on the baseplate. The excitation point (point A) is 


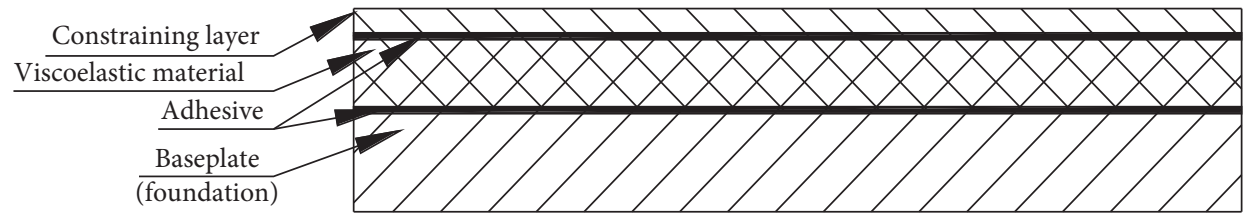

FIGURE 1: Sketch of sandwich plate.

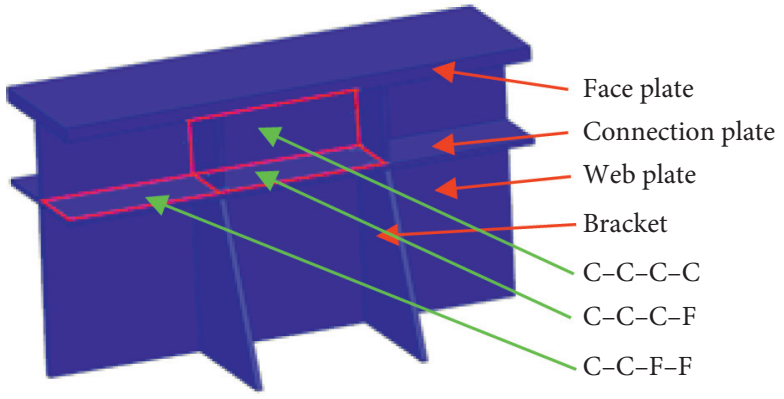

(a)

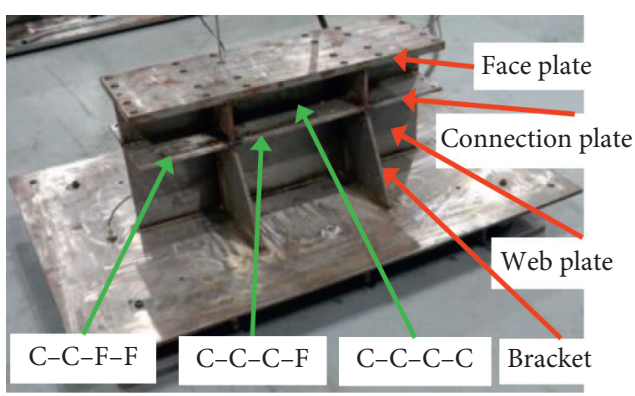

(b)

FIgURE 2: Schematic diagram and physical picture of an equipment base. (a) Schematic diagram. (b) Physical picture.

Table 1: Parameters of the EMWM specimens.

\begin{tabular}{|c|c|c|c|c|c|c|}
\hline Density $\left(\mathrm{kg} / \mathrm{m}^{3}\right)$ & Length $(\mathrm{mm})$ & Width $(\mathrm{mm})$ & Thickness $(\mathrm{mm})$ & Weight $(\mathrm{kg})$ & Molding pressure $(\mathrm{kN})$ & Batch \\
\hline \multirow{3}{*}{2000} & \multirow{3}{*}{150} & \multirow{3}{*}{150} & 4 & 0.18 & 132.8 & 1 \\
\hline & & & 6 & 0.27 & 150.6 & 2 \\
\hline & & & 8 & 0.36 & 156.3 & 3 \\
\hline
\end{tabular}

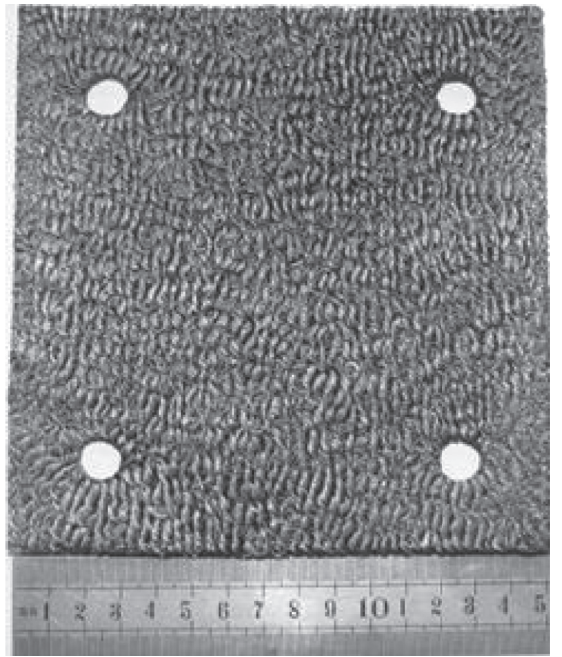

(a)

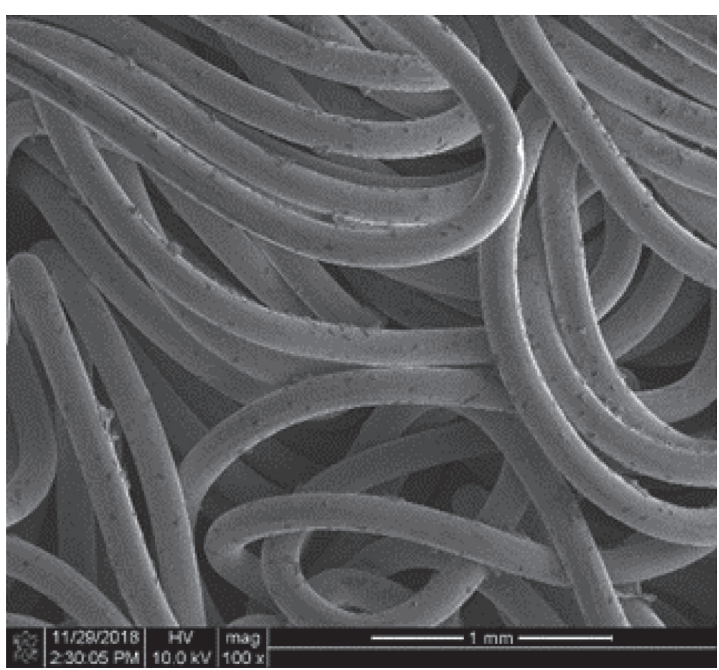

(b)

Figure 3: EMWM specimen. (a) EMWM layer. (b) SEM image of the EMWM $(100 \times$ enlargement).

located at the center of the damping composite area of the baseplate. Four M6 bolts (points B1 B4) are used to mount the baseplate, EMWM layer, and the constraining plate together.

The composite structure with EMWM layer is shown in Figure 6. The real structure is shown in Figure 6. The bottom is the baseplate, the middle is the EMWM layer, and the top is the constraining plate. The limit block is used to compress the EMWM layer by the same amount of $2 \mathrm{~mm}$. The baseplate, EMWM layer, limit block, and constraint plate are constrained and fixed by four bolts. Through holes are arranged on the baseplate, and the 


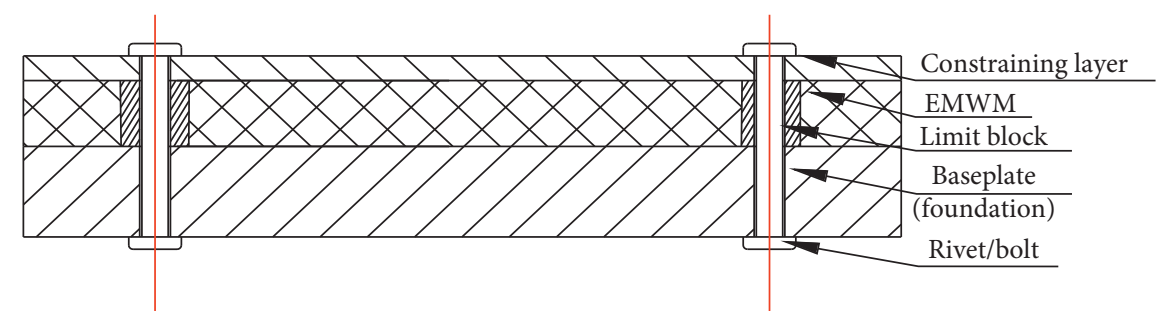

Figure 4: Composite structure with EMWM layer.

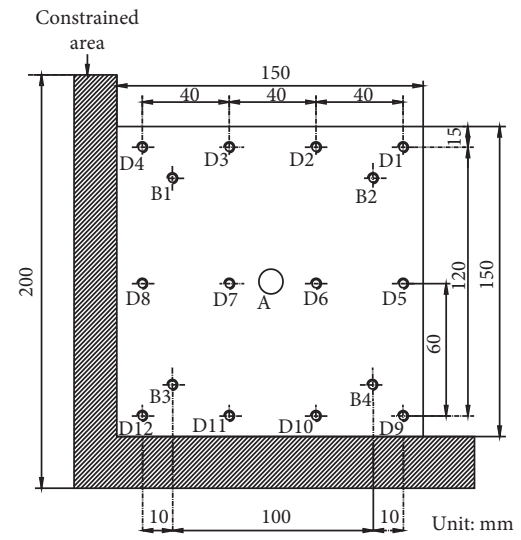

(a)

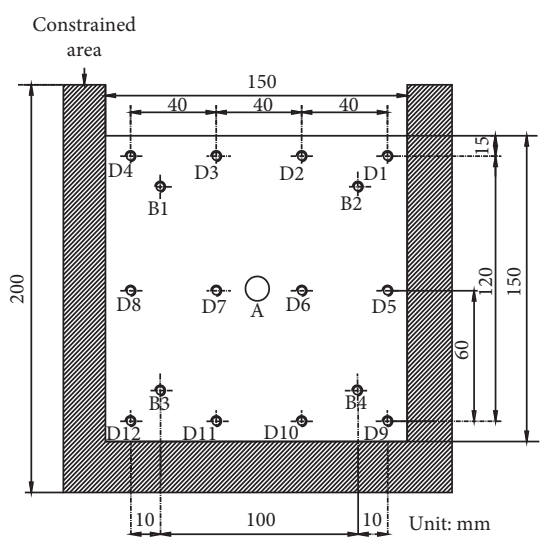

(b)

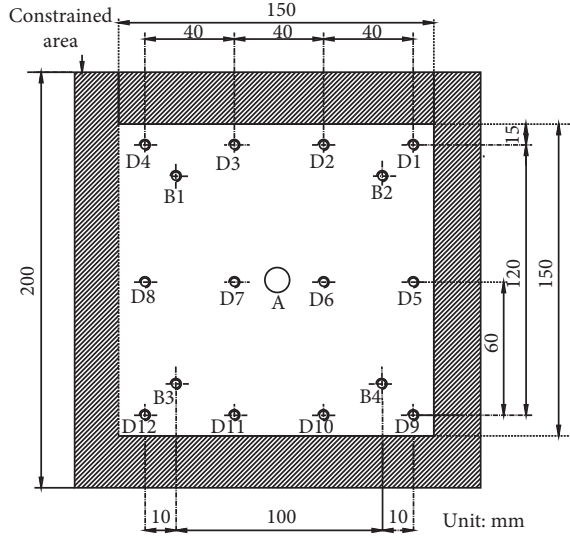

(c)

Figure 5: Dimensions of the baseplate under different boundary conditions. (a) Two ends clamped (C-C-F-F), (b) three ends clamped (C-C$\mathrm{C}-\mathrm{F})$, and (c) four ends clamped (C-C-C-C).

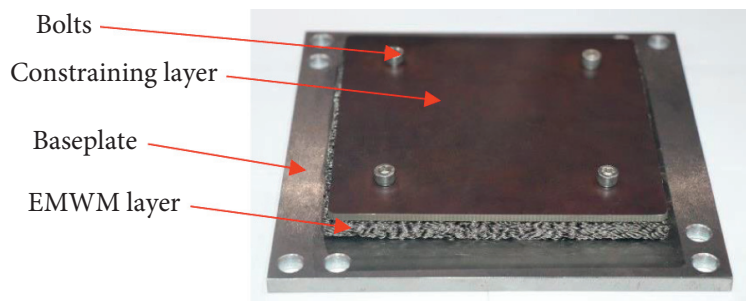

FIGURE 6: Image of the composite structure with EMWM layer.

boundary restraint is performed by the pair of supporting beams and restraining beams. Figure 6 shows the physical assembly of the four-sided constraint of the actual structure.

2.2. Damping Property of EMWM. In this research, loss factor $\eta$ is used to characterize the damping property of EMWM; quasi-static compression test is used to test the loss factor $(\eta)$.

Figure 7 shows the hysteretic loop for EMWM of a quasistatic compression test. It is evident that the unloading curve does not coincide with the loading curve. This is caused by the dry friction between the internal wire helixes. The shaded area surrounded by loading and unloading curves $(\Delta W)$ represents the energy dissipated by EMWM in one test cycle (Figure 7). The shaded area $U$ represents the maximum deformation energy stored in one test cycle (Figure 7 ).
Therefore, the loss factor of EMWM $(\eta)$ can be expressed as follows:

$$
\eta=\frac{\Delta W}{\pi U}
$$

The quasi-static compression test for each EMWM specimen was conducted by using a computerized electronic universal testing equipment (WDW-T200). WDW-T200 was manufactured by Jinan Tianchen Testing Machine Manufacturing Co., Ltd., China. WDW-T200 is used in displacement control mode with a constant speed $(1 \mathrm{~mm} / \mathrm{min})$. To control the test variables, the maximum loading force was set as $35 \mathrm{KN}$.

The loss factor of each EMWM specimen is shown in Table 2. It is obvious that the loss factor increases with the increase in the thickness of the EMWM. As the number of the contact points grows with the increase of thickness, the EMWM can absorb more vibrating energy during one cycle, 


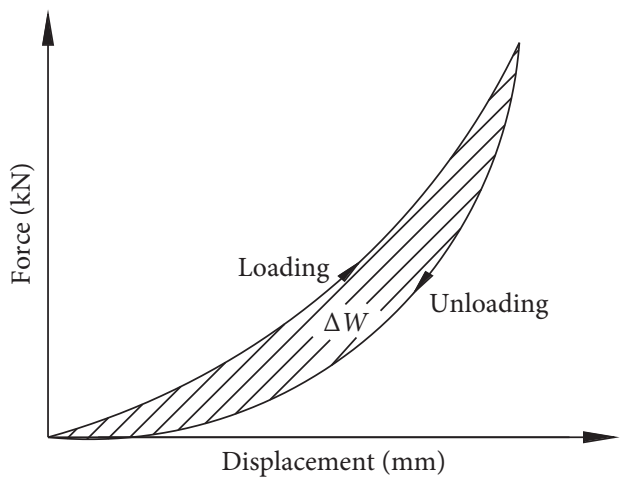

(a)

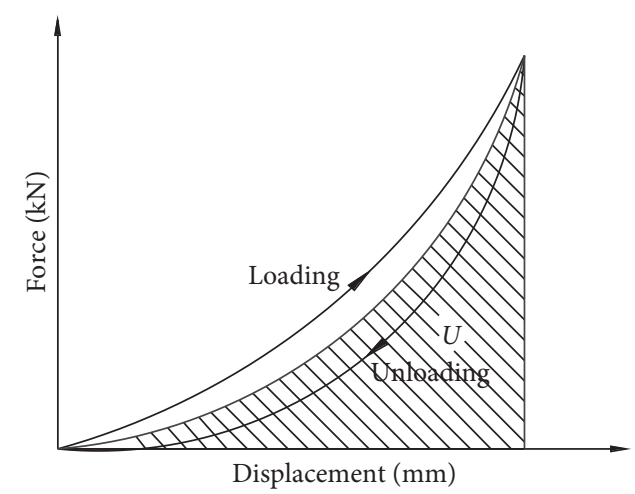

(b)

Figure 7: Sketch of the hysteresis loop for EMWM. (a) Energy consumption in one test cycle; (b) maximum deformation energy stored in one test cycle.

TABLE 2: Loss factor of EMWM specimens with their standard deviations.

\begin{tabular}{lccc}
\hline Batch & Thickness $(\mathrm{mm})$ & Mean value & Standard deviation \\
\hline 1 & 4 & 0.1007 & 0.001 \\
2 & 6 & 0.13 & 0.0012 \\
3 & 8 & 0.1375 & 0.0014 \\
\hline
\end{tabular}

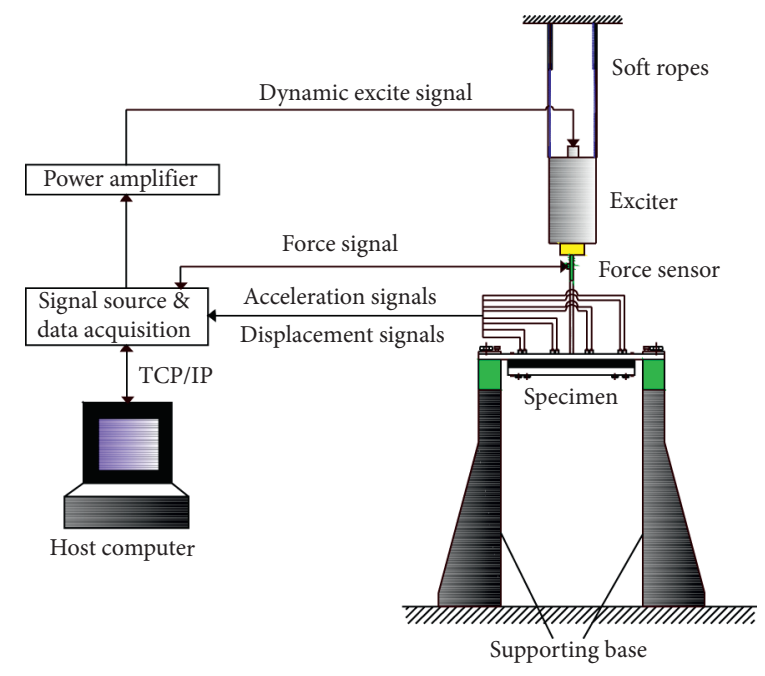

Figure 8: Schematic of the modal test system.

which means that the EMWM with a bigger thickness has a better damping performance. It can also be seen from Table 2 that the standard deviation of each batch is small. It means that all specimens have consistency.

\section{Experimental Apparatus and Methods}

3.1. Experimental Modal Test System. As shown in Figure 8, an experimental modal test system was set up for two purposes: (1) verifying whether there is a displacement deviation between the baseplate and the constraining plate of the composite structure to change the compression state of the EMWM layer and consequently lead to energy dissipation; (2) testing the modal characteristics of composite structures with different core thicknesses under different boundary conditions.

The experimental modal test system was mainly composed of a signal source and data acquisition system, a power amplifier, an electromagnetic vibration exciter, and composite structure. For the first test purpose (1), a pair of eddy current displacement sensors were used to measure the displacement response of the baseplate and the constraining plate at the 12 measure points, respectively (Figure 9). For the second test purpose (2), 12 accelerometers were used to detect the acceleration response of baseplate.

The test principle is as follows: (a) the operator installs the composite structure into the test system according to the 


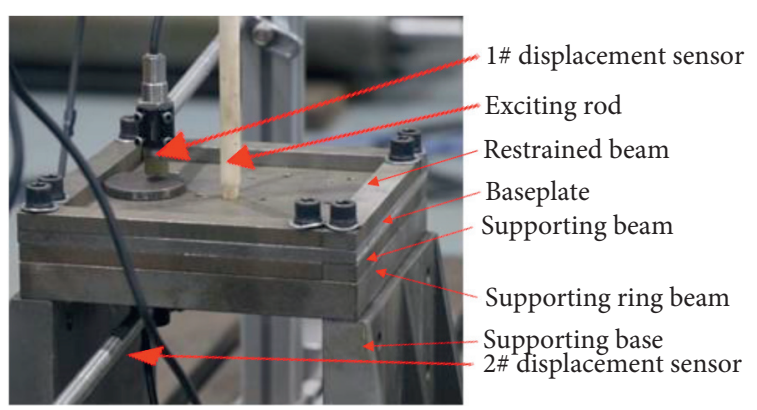

Figure 9: Displacement deviation test system.

target boundary condition; (b) the operator sets the experimental parameters on the host computer; (c) the output channels of signal source and data acquisition system generate the corresponding excitation signal; (d) the power amplifier amplifies the signal and then transmits the amplified signal to the electromagnetic vibration exciter; (e) the composite structure received dynamical excitation from the electromagnetic vibration exciter; (f) the signal source and data acquisition system acquires the displacement signals (or acceleration signals) and force signals and sends them to the host computer for postprocessing and storage.

Technical specifications of the main equipment for the test system are as follows:

(1) Signal generation and acquisition system: the signal source and data acquisition system (uT8916FRS-DY) was developed by uTekl (Wuhan, China). uT8916FRSDY has two output channels for generating a sinusoidal sweeping signal and has sixteen input channels for collecting force/displacement/acceleration signals.

(2) Electromagnetic vibration exciter: an electromagnetic vibration exciter JZQ-50 is provided with ECON power amplifier (Hangzhou, China). The maximum exciting force was $500 \mathrm{~N}$ and the maximum output power was 800 watts.

(3) Force measurement: a YD-303 piezoelectric type quartz force sensor (Yangzhou, China). Its resonant frequency was more than $60 \mathrm{KHz}$ and it had a charge sensitivity of $3.08 \mathrm{pC} / \mathrm{N}$.

(4) Displacement measurement: two KD9002 eddy current displacement sensors (Yangzhou, China). The parameters of the KD9002 are as follows: the sensitivity was $8 \mathrm{mv} / \mu \mathrm{m}$, the measuring distance was $2 \mathrm{~mm}$, and the resolution was $0.4 \mu \mathrm{m}$.

(5) Acceleration measurement: twelve 1A102 E piezoelectric type accelerometers (Jingjiang, China). The parameters of the accelerometer are as follows: the sensitivity was $10.36 \mathrm{mV} / \mathrm{g}$, and the measuring range was $\pm 500 \mathrm{~g}$.

3.2. Experimental Method. The parameters of the excitation signal are given in Table 3.

3.2.1. Displacement Deviation Test. 12 sinusoidal sweep tests were carried out with the change the position of the pair of
TABle 3: Parameters of the excitation signal.

\begin{tabular}{lc}
\hline Parameters & Numerical value \\
\hline Amplitude & $100 \mathrm{~N}$ \\
Waveform & Sine \\
Sweep mode & Logarithmic \\
Sweep range & $10 \sim 500 \mathrm{~Hz}$ \\
Sweep cycle & $40 \mathrm{~s}$ \\
\hline
\end{tabular}

eddy current displacement sensors from measure point D1 to D12. The displacement deviations between the baseplate and the constraining plate at D1 D12 were collected by uT8916FRS-DY.

3.2.2. Modal Test. To verify the improvement of the vibration and damping characteristics of the steel plate (baseplate) by adding composite structure, a series of comparisons of the modal tests for steel plate (baseplate) and composite structure with different core thicknesses were carried out under different boundary conditions. The responses of the baseplate and composite structure were detected through 12 accelerometers. The response signals were recorded and processed by the use of uT8916FRS-DY in real time.

At the end of excitation, the time-frequency response function can be obtained by postprocessing with the timefrequency joint analysis technology [31]. Therefore, the effect of core thickness and boundary condition on the modal characteristics of the baseplate and composite structure can be obtained. Furthermore, the damping ratio $(\xi)$ of the baseplate (steel plate) and composite structure can be obtained by the half-power band width method.

$$
2 \xi=\frac{\omega_{2}-\omega_{1}}{\omega_{n}},
$$

where $\omega_{n}$ is the $n$-order modal frequency of the structure and $\omega_{1}$ and $\omega_{2}$ are the excitation frequencies corresponding to the half-power point.

\section{Test Results and Discussion}

4.1. Displacement Deviation of the Composite Structure. The displacement deviations between the baseplate and the constraining plate at different measure points (D1 D D $)$ were detected. Take data at measure point D1 as an example to analyze the relationship between displacement deviation and frequency (note: the thickness of EMWM is $4 \mathrm{~mm}$ ).

Figure 10 shows the displacement response at the measure point D1 of the baseplate and the constraining plate under different boundary conditions. Two conclusions can be drawn from Figure 10. First, the maximum displacement of the constraining plate is far less than $1 \mu \mathrm{m}$; thus the displacement deviation between the baseplate and constraining plate is approximately the displacement of the baseplate. Second, the displacement deviations in the first two-order modal frequencies are significant. Under different boundary conditions, the maximum displacement deviations are over $30 \mu \mathrm{m}$ in the first-order modal frequency, and those in the second- 


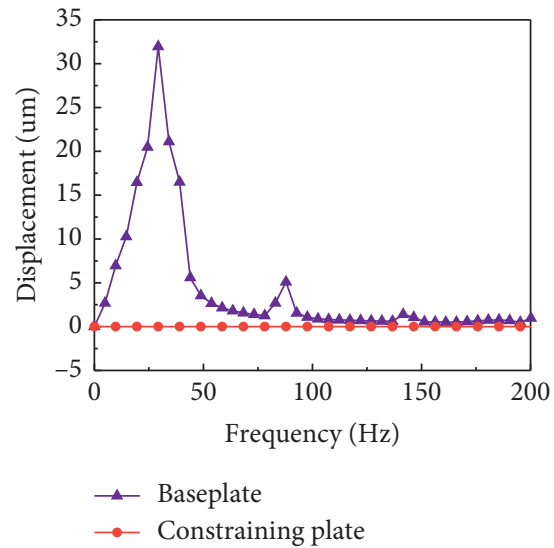

(a)

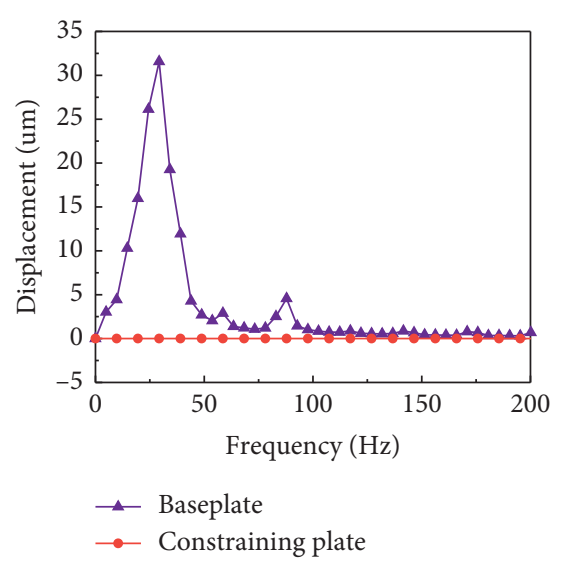

(b)

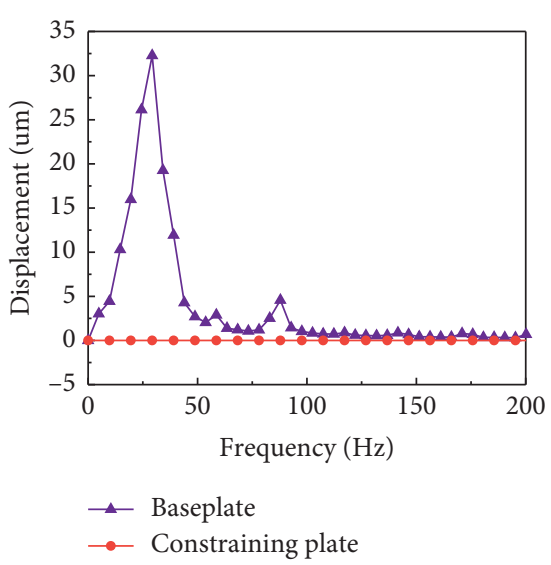

(c)

Figure 10: Displacement response of the baseplate and the constraining plate under three different boundary conditions (measure point D1). (Note: the displacement direction is positive in the vertical direction and negative in the opposite direction). (a) C-C-F-F, (b) C-C-C-F, and (c) C-C-C-C.

order modal frequency are over $5 \mu \mathrm{m}$. As illustrated above, when the EMWM is deformed in the micron scale, the internal wire helixes of EMWM will slip and lead to energy dissipation [32]. Therefore, when the composite structure with EMWM layer was excited by an external force, the vibration energy will be dissipated in the form of friction between wire helixes inside the EMWM. Thus, with the increase of deformation, the EMWM can absorb more vibrating energy during one cycle, which means that the composite structure with a bigger displacement deviation has a better damping performance. The maximum displacement deviation at the third-order modal frequency is around $1 \mu \mathrm{m}$; thus, the energy dissipation at the third modal frequency can be neglected. The displacement deviations of the composite structure with EMWM $(4 \mathrm{~mm})$ layer at different measure points (D1 D12) under different boundary conditions are shown in Table 4 . The same conclusion can be drawn from Table 4 . It can be seen from Table 4 that the standard deviation of each measuring point was obviously smaller than the mean value, which indicates that the discretization of the data is small (note: detailed test data can be found in the appendix of this paper.)

\subsection{Modal Characteristics of the Composite Structure}

4.2.1. Effect on Modal Frequency. Figure 11 shows the first three-order modal frequencies of steel plate (baseplate) and composite structure with different core thicknesses under different boundary conditions. As illustrated in the figure, the first three second-order modal frequencies of the composite structures are significantly lower than that of the steel plate (baseplate).

The natural frequency of vibration without damping $f_{n}$ can be expressed as follows:

$$
f_{n}=\frac{1}{2 \pi} \sqrt{\frac{k}{m}} .
$$

The natural frequency of vibration with damping $f_{n}^{\prime}$ can be expressed as follows:

$$
f_{n}^{\prime}=f_{n} \sqrt{1-\xi^{2}},
$$

where $\xi$ is the damping ratio.

It can be seen from equations (3) and (4) that, under the same boundary condition, the natural frequencies of the structure are influenced by mass $(m)$, stiffness $(k)$, and damping ratio $(\xi)$. The composite structure studied in this paper is to add an EMWM layer and a constraining plate on the original steel plate. Thus, the mass of the composite structure was larger than that of the original steel plate. The stiffness of the EMWM is much less than that of 45 steel. The clamped ends of the composite structure are still the original steel plate; thus the stiffness changes little. The influence of the changes of structural mass has a greater effect on frequency than that of the changes of stiffness. As illustrated in Table 2, the loss factor of the EMWM specimen is in the range from 0.1007 to 0.1375 , while the loss factor of 45 steel is less than 0.02 [33]. EMWM is an elastic damping material that will increase the damping ratio of the structure. It can be seen from equation (4) that the natural frequency of the structure would decrease by adding EMWM layer. As a consequence, the first three-order modal frequencies of the composite structures are lower than that of the original steel plate.

As illustrated in Figure 11, under the same boundary condition, the modal frequency of the structure decreases with the increases of core thickness, and this is due to the effect of thickness on the damping performance of the EMWM shown above in Table 2. It also can be seen from Figure 11 that the boundary conditions also affect the modal frequencies of structures. At the first-order modal frequency, the modal frequency of the structure under C-C-F-F boundary condition is lower than those of other boundary conditions. This 
TABLE 4: Displacement deviation at measure points (D1 D12) under different boundary conditions. (unit: $\mu \mathrm{m})$.

\begin{tabular}{|c|c|c|c|c|c|c|c|c|c|c|c|c|c|c|c|c|c|c|}
\hline & \multicolumn{6}{|c|}{ C-C-C-C } & \multicolumn{6}{|c|}{ C-C-C-F } & \multicolumn{6}{|c|}{ C-C-F-F } \\
\hline & \multicolumn{2}{|c|}{ First order } & \multicolumn{2}{|c|}{$\begin{array}{l}\text { Second } \\
\text { order }\end{array}$} & \multicolumn{2}{|c|}{ Third order } & \multicolumn{2}{|c|}{ First order } & \multicolumn{2}{|c|}{$\begin{array}{l}\text { Second } \\
\text { order }\end{array}$} & \multicolumn{2}{|c|}{ Third order } & \multicolumn{2}{|c|}{ First order } & \multicolumn{2}{|c|}{$\begin{array}{l}\text { Second } \\
\text { order }\end{array}$} & \multicolumn{2}{|c|}{ Third order } \\
\hline & MV & SD & MV & SD & MV & SD & MV & SD & MV & SD & MV & SD & MV & SD & MV & SD & MV & SD \\
\hline D1 & 32.26 & 0.113 & 4.79 & 0.076 & 1.45 & 0.098 & 31.56 & 0.035 & 5.07 & 0.092 & 0.86 & 0.137 & 31.94 & 0.073 & 5.09 & 0.091 & 1.01 & 0.134 \\
\hline D2 & 32.31 & 0.147 & 5.04 & 0.154 & 1.62 & 0.142 & 31.49 & 0.027 & 5.22 & 0.107 & 0.82 & 0.144 & 31.86 & 0.182 & 5.04 & 143 & 0.99 & .097 \\
\hline D3 & 32.29 & 0.125 & 4.94 & 0.095 & 1.71 & 0.117 & 31.44 & 0.056 & 5.27 & 0.113 & 1.06 & 0.202 & 31.77 & 0.061 & 5.03 & 0.112 & 0.99 & 0.137 \\
\hline D4 & 32.22 & 0.118 & 4.97 & 0.082 & 1.32 & 0.134 & 31.45 & 0.043 & 5.33 & 0.086 & 1.13 & 0.183 & 30.72 & 0.062 & 5.11 & 0.083 & 1.12 & 0.146 \\
\hline D5 & 31.93 & 0.094 & 4.83 & 0.106 & 1.67 & 0.187 & 31.49 & 0.022 & 5.31 & 0.094 & & 0 & 31.82 & 0.124 & 5.08 & 37 & 0.97 & 0.133 \\
\hline D6 & 32.18 & 0.157 & 5.22 & 0.233 & 1.75 & 0.143 & 31.55 & 0.016 & 5.41 & 0.083 & 1.27 & 0.134 & 31.79 & 0.153 & 5.02 & 0.224 & 1.08 & 0.212 \\
\hline D7 & 32.44 & 0.201 & 5.31 & 0.162 & 1.82 & 0.126 & 31.52 & 0.047 & 5.43 & 0.117 & 1.18 & 0.246 & 31.55 & 0.115 & 5.04 & 0.068 & 1.03 & 0.107 \\
\hline D8 & 31.97 & 0.193 & 5.09 & 0.066 & 1.87 & 0.132 & 31.49 & 0.028 & 5.13 & 0.104 & 1.21 & 0.209 & 31.23 & 0.092 & 4.95 & 0.047 & 1.15 & 0.093 \\
\hline D9 & 32.05 & 0.115 & 4.85 & 0.074 & 1.37 & 0.145 & 31.55 & 0.043 & 5.06 & 0.097 & 0.91 & 0.177 & 30.53 & 0.146 & 4.89 & 0.118 & 1.03 & 0.278 \\
\hline D10 & 32.12 & 0.174 & 4.92 & 0.096 & 1.58 & 0.184 & 31.48 & 0.034 & 5.17 & 0.105 & 0.92 & 0.092 & 30.76 & 0.128 & 4.91 & 0.132 & 0.89 & 0.139 \\
\hline D11 & 32.17 & 0.164 & 5.18 & 0.118 & 1.65 & 0.088 & 31.45 & 0.053 & 4.96 & 0.132 & 0.99 & 0.106 & 31.02 & 0.079 & 4.88 & 0.124 & 0.93 & 0.223 \\
\hline D12 & 32.09 & 0.247 & 5.11 & 0.125 & 1.51 & 0.139 & 31.44 & 0.064 & 5.34 & 0.109 & 0.87 & 0.102 & 30.44 & 0.134 & 4.76 & 0.083 & 0.86 & 0.064 \\
\hline
\end{tabular}

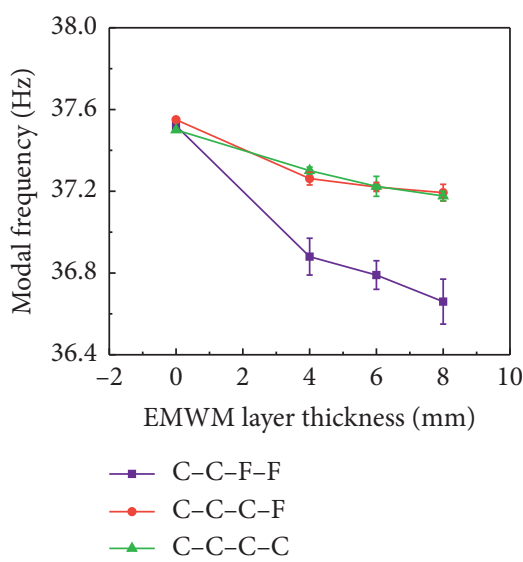

(a)

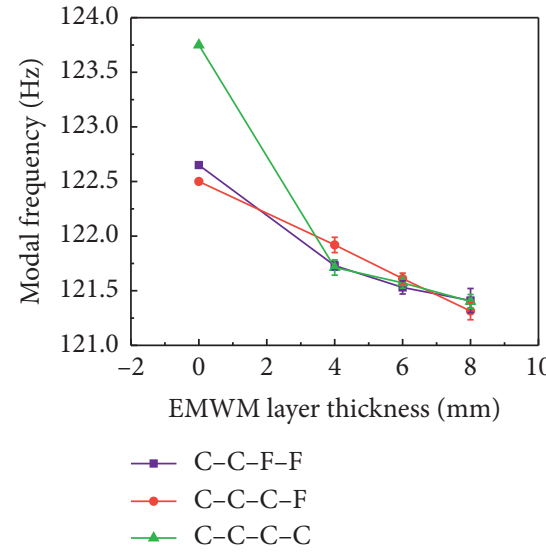

(b)

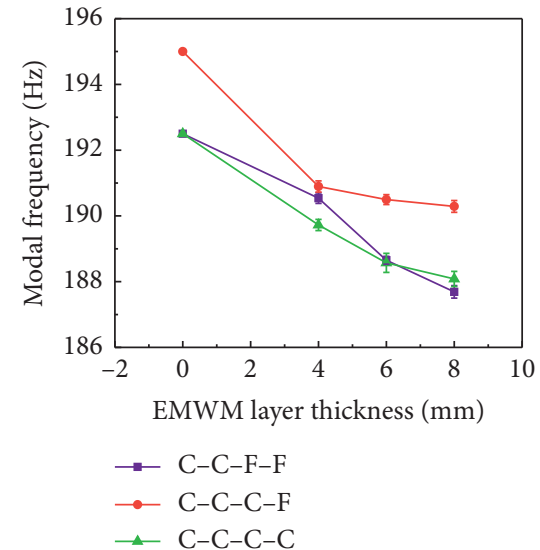

(c)

Figure 11: The first three modal frequencies of the steel plate (baseplate) and composite structures with different core thicknesses under different boundary conditions. (a) First order, (b) second order, and (c) third order.

phenomenon is due to the fact that the stiffness of the structure is affected by boundary conditions.

4.2.2. Effect on Damping Ratio. Figure 12 presents the damping ratios of the steel plate and composite structures at the first three-order modal frequencies.

It can be seen from Figure 12 that, under different boundary conditions, the damping ratios at the first-order modal frequency of the composite structures are significantly larger than that of the baseplate (thickness of $8 \mathrm{~mm}$ ), and the damping ratio grows with the increase of the core thickness. It indicates that the damping characteristics of the structure would be changed by adding an EMWM layer and affected by the thickness of the EMWM layer. In the secondand third-order modal frequencies, the changes of the damping ratio are not obvious as that in the first-order modal frequency. This is due to the fact that the displacement deviations between the baseplate and constraining plate in the second- and third-order modal frequency are far less than that at the first-order modal frequency (Table 4). As illustrated above, the larger the displacement deviation the better damping performance. Furthermore, the effect of boundary conditions on the damping ratio is not as obvious as that of core thickness.

4.2.3. Effect on Modal Shape. First three-order modal shapes of the baseplate and composite structures can be deduced from the vibration response of the baseplate and composite structures. It can be seen from Table 5 that the EMWM layer and the constraining plate would change the modal shapes of the original structure.

4.3. Vibration Reduction Performance. Frequency response curves (FRCs) for acceleration of the baseplate and composite structures with different core thicknesses under different boundary conditions were obtained by signal source and data acquisition system (uT8916FRS-DY) in real time. The FRCs for acceleration of the original steel plate (baseplate) $(8 \mathrm{~mm})$ at different measuring points are shown in Figure 13. The amplitude of FRCs for acceleration at the 


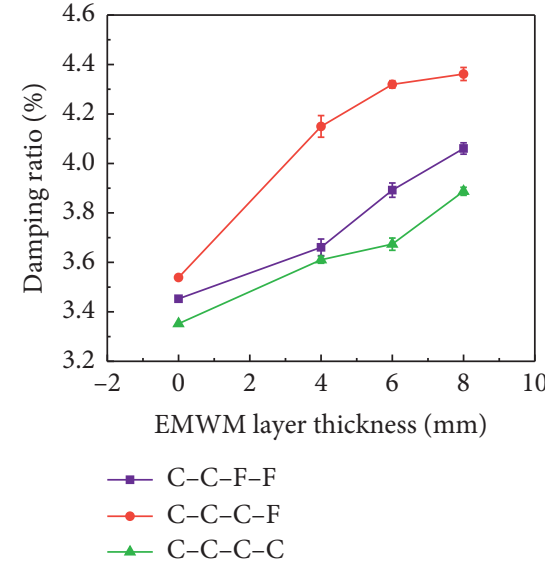

(a)

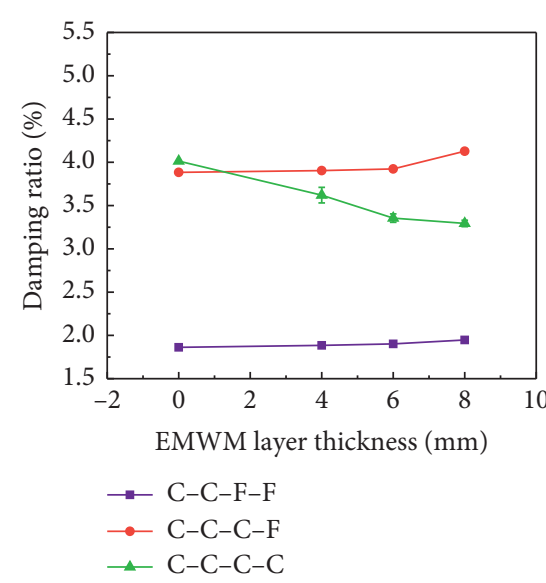

(b)

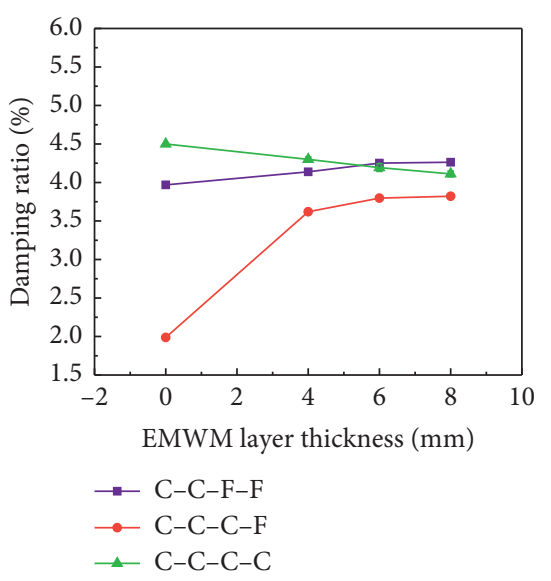

(c)

Figure 12: The damping ratios of the steel plate (baseplate) and composite structures with different core thicknesses under different boundary conditions. (a) First order, (b) second order, and (c) third order.

TABLE 5: First three-order modal shapes of the baseplate and composite structures under different boundary conditions.

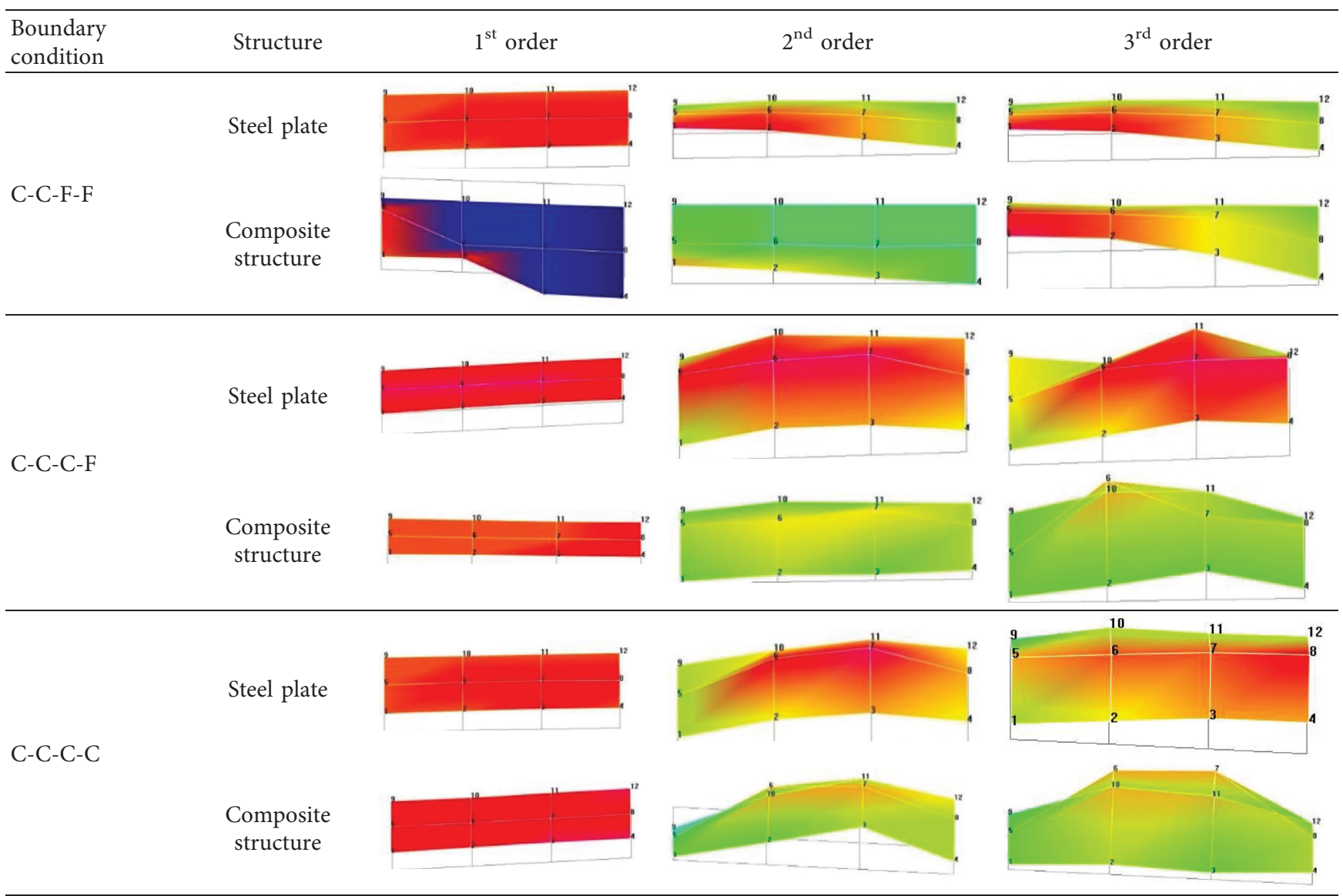

first-order modal frequency was larger than those in the second- and third-order modal frequency. It also can be seen that the amplitude of FRCs of each measurement point at the first frequency almost coincides. Thus, the following will compare the vibration responses of the structures in the firstorder modal frequency.
The stiffness and damping factor are two key parameters that affect the vibration response of the structure. Figure 14 shows the FRC of the baseplate and composite structures at the first modal frequency under different boundary conditions (measure point D1). It can be clearly seen that the amplitude of FRC can be reduced by adding EMWM. 


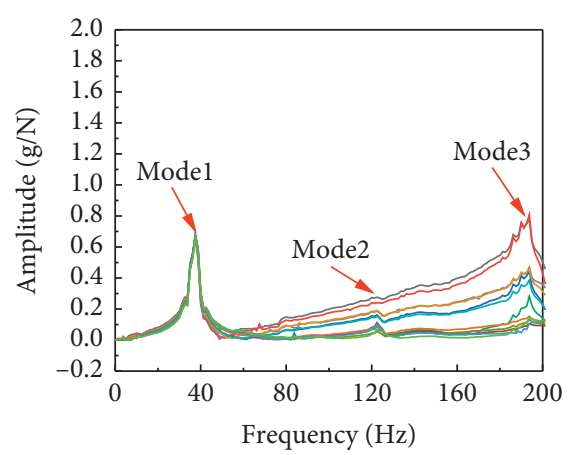

$\begin{array}{lll}\text { D1 } & -\mathrm{D} 5 & -\mathrm{D} 9 \\ \mathrm{D} 2 & -\mathrm{D} 6 & -\mathrm{D} 10 \\ \mathrm{D} 3 & -\mathrm{D} 7 & \mathrm{D} 11 \\ \mathrm{D} 4 & \mathrm{D} 8 & \mathrm{D} 12\end{array}$

(a)

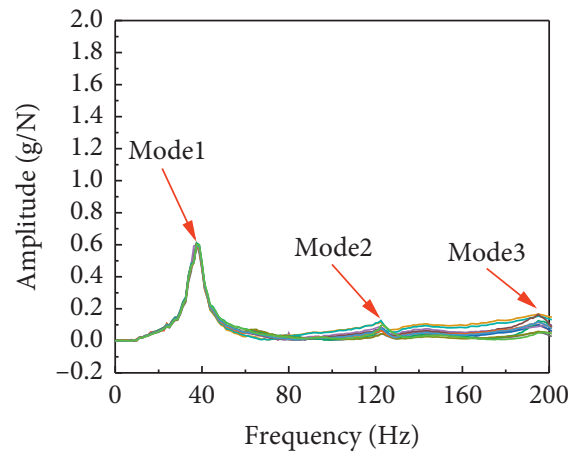

$\begin{array}{lll}-\mathrm{D} 1 & -\mathrm{D} 5 & -\mathrm{D} 9 \\ \mathrm{D} 2 & -\mathrm{D} 6 & \mathrm{D} 10 \\ \mathrm{D} 3 & -\mathrm{D} 7 & \mathrm{D} 11 \\ \mathrm{D} 4 & -\mathrm{D} 8 & \mathrm{D} 12\end{array}$

(b)

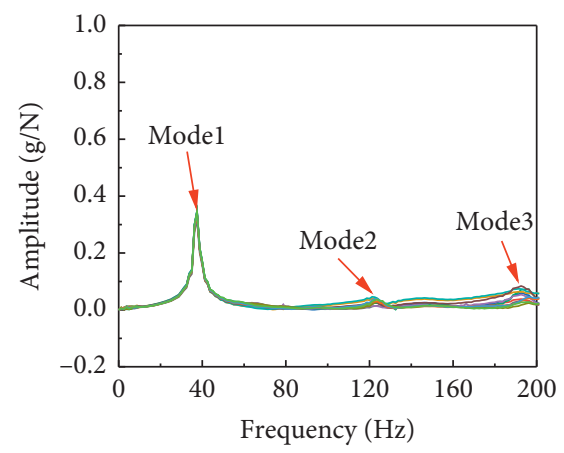

$\begin{array}{lll}\text { D1 } & -\mathrm{D} 5 & -\mathrm{D} 9 \\ \mathrm{D} 2 & -\mathrm{D} 6 & \mathrm{D} 10 \\ \mathrm{D} 3 & -\mathrm{D} 7 & -\mathrm{D} 11 \\ \mathrm{D} 4 & -\mathrm{D} 8 & -\mathrm{D} 12\end{array}$

(c)

FIGURE 13: The FRCs of steel plate (baseplate) under different boundary conditions at different measuring points. (a) C-C-F-F, (b) C-C-C-F, and (c) C-C-C-C.

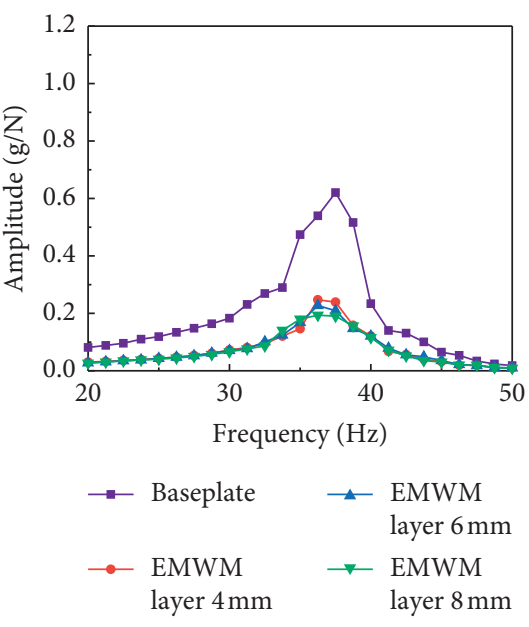

(a)
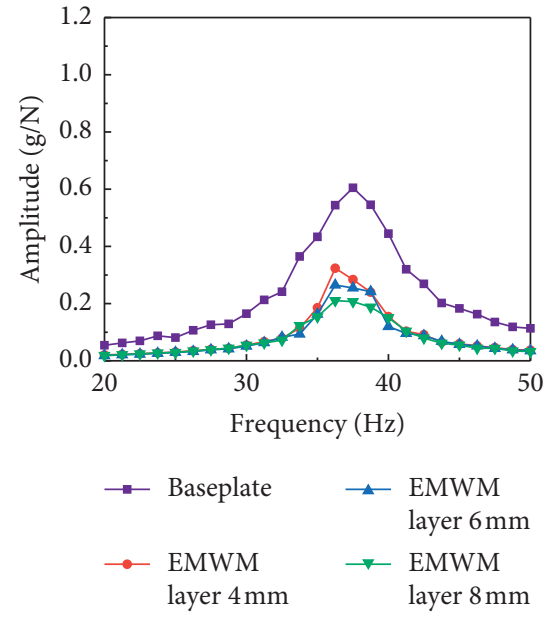

(b)

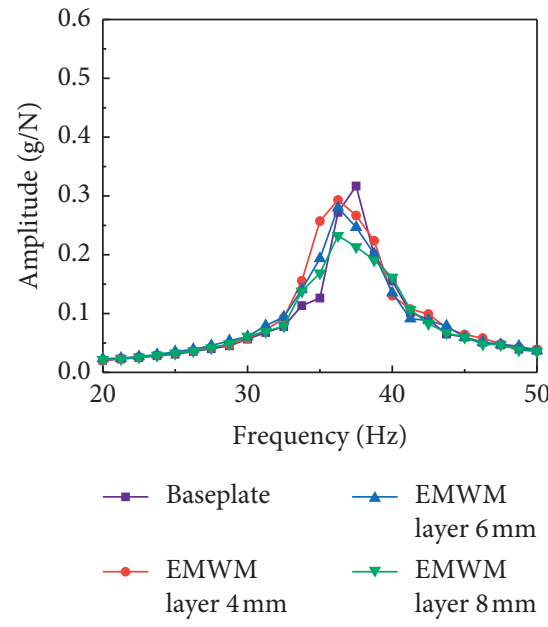

(c)

FIGURE 14: The FRCs of the baseplate and composite structures at $1^{\text {st }}$-order modal frequency under different boundary conditions (D1). (a) C-C-F-F, (b) C-C-C-F, and (c) C-C-C-C.

Furthermore, the amplitude decreases with the increases of core thickness. Under the boundary condition of C-C-F-F and C-C-C-F, the amplitude can be reduced by $60.19 \%$ $67.74 \%$ and $46.47 \% \sim 64.18 \%$, respectively. Under the boundary condition of C-C-C-C, the amplitude is only reduced by $6.45 \% \sim 25.81 \%$. There are two reasons for the reduction: first, the stiffness of the baseplate was improved by adding EMWM layer and constraining layer; second, the EMWM is a kind of damping material and can dissipate vibration energy in the form of friction between the internal wire helixes. The influence of core thickness on the vibration reduction is consistent with the analysis results of the loss factor. The original stiffness of the baseplate is the largest under the condition of $\mathrm{C}-\mathrm{C}-\mathrm{C}-\mathrm{C}$, so the effect of increasing stiffness and damping by adding EMWM layer and constraining plate is not obvious enough. Therefore, the amplitude attenuation of FRCs under $\mathrm{C}-\mathrm{C}-\mathrm{C}-\mathrm{C}$ condition is less than that under the other boundary conditions.

\section{Conclusion}

To reduce the vibration of the plate-like structure, a new composite structure was presented by adding EMWM layer and constraining plate. The damping performance of the EMWM was tested by a series of quasi-static compression tests. A dynamic test system was set up to verify that the displacement deviation between baseplate and constraining plate is sufficient to cause the energy dissipation of EMWM. The modal characteristics of the baseplate and composite structures with different core thicknesses under different 
boundary conditions were investigated. The main conclusions, which can be drawn from the conducted experiments, are as follows:

(1) The displacement deviations between the baseplate and constraining plate are sufficient to cause the energy dissipation of EMWM.

(2) Adding EMWM and constraining plate will reduce the modal frequency of the structure. Furthermore, the damping ratio of the structure would be significantly improved, and the amplitude of the FRF curve can be reduced.

(3) The larger the thickness of the core thickness is, the larger the damping ratio and vibration reduction performance of the composite structure are.

(4) The effect of EMWM on the vibration and damping characteristics of the composite structure under the boundary condition of C-C-C-C is not as obvious as that under the other boundary conditions.

\section{Data Availability}

The data used to support the findings of this study are available from the corresponding author upon request.

\section{Conflicts of Interest}

The authors declare that they have no conflicts of interest.

\section{Acknowledgments}

This work was supported by the National Natural Science Foundation of China (Grant no. 51805086) and the Natural Science Foundation of Fujian Province, China (Grant no. 2018J01763).

\section{Supplementary Materials}

Displacement deviation at measure points (D1 D12) under different boundary conditions: (a) measure point D1; (b) measure point D2; (c) measure point D3; (d) measure point D4; (e) measure point D5; (f) measure point D6; (g) measure point D7; (h) measure point D8; (i) measure point D9; (j) measure point D10; (k) measure point D11; (l) measure point D12; (unit: $\mu \mathrm{m})$. (Supplementary Materials)

\section{References}

[1] L. Irazu and M. J. Elejabarrieta, "The influence of viscoelastic film thickness on the dynamic characteristics of thin sandwich structures," Composite Structures, vol. 134, pp. 421-428, 2015.

[2] L. Irazu and M. J. Elejabarrieta, "The effect of the viscoelastic film and metallic skin on the dynamic properties of thin sandwich structures," Composite Structures, vol. 176, pp. 407-419, 2017.

[3] A. Z. Deng and F. K. Li, "Research progress on damping properties of sandwich composites," Materials Review, vol. 31, pp. 165-171, 2017.

[4] V. D'Alessandro, G. Petrone, F. Franco, and S. De Rosa, “A review of the vibroacoustics of sandwich panels: models and experiments," Journal of Sandwich Structures \& Materials, vol. 15, no. 5, pp. 541-582, 2013.

[5] E. Fotsing, M. Sola, A. Ross, and E. Ruiz, "Lightweight damping of composite sandwich beams: experimental analysis," Journal of Composite Materials, vol. 47, no. 12, pp. 1501-1511, 2013.

[6] J. Yang, J. Xiong, L. Ma, B. Wang, G. Zhang, and L. Wu, "Vibration and damping characteristics of hybrid carbon fiber composite pyramidal truss sandwich panels with viscoelastic layers," Composite Structures, vol. 106, pp. 570-580, 2013.

[7] Y. Bai, K. Yu, J. Zhao, and R. Zhao, "Experimental and simulation investigation of temperature effects on modal characteristics of composite honeycomb structure," Composite Structures, vol. 201, pp. 816-827, 2018.

[8] Z. Huang, Z. Qin, and F. Chu, "Damping mechanism of elastic-viscoelastic-elastic sandwich structures," Composite Structures, vol. 153, pp. 96-107, 2016.

[9] M. Assarar, W. Zouari, R. Ayad, H. Kebir, and J.-M. Berthelot, "Improving the damping properties of carbon fibre reinforced composites by interleaving flax and viscoelastic layers," Composites Part B: Engineering, vol. 152, pp. 248-255, 2018.

[10] A. Treviso, B. Van Genechten, D. Mundo, and M. Tournour, "Damping in composite materials: properties and models," Composites Part B: Engineering, vol. 78, pp. 144-152, 2015.

[11] H. Yu, X. Sun, J. Xu, and S. Zhang, "Transition sets analysis based parametrical design of nonlinear metal rubber isolator," International Journal of Non-Linear Mechanics, vol. 96, pp. 93-105, 2017.

[12] Y. Ma, Q. Zhang, D. Zhang, F. Scarpa, B. Liu, and J. Hong, "Tuning the vibration of a rotor with shape memory alloy metal rubber supports," Journal of Sound and Vibration, vol. 351, pp. 1-16, 2015.

[13] D. Rodney, B. Gadot, O. R. Martinez, S. Rolland Du Roscoat, and L. Orgéas, "Reversible dilatancy in entangled single-wire materials," Nature Materials, vol. 15, no. 1, pp. 72-77, 2016.

[14] B. Gadot, O. Riu Martinez, S. Rolland Du Roscoat, D. Bouvard, D. Rodney, and L. Orgéas, "Entangled single-wire NiTi material: a porous metal with tunable superelastic and shape memory properties," Acta Materialia, vol. 96, pp. 311-323, 2015.

[15] Y. Ma, Q. Zhang, D. Zhang, F. Scarpa, D. Gao, and J. Hong, "Size-dependent mechanical behavior and boundary layer effects in entangled metallic wire material systems," Journal of Materials Science, vol. 52, no. 7, pp. 3741-3756, 2017.

[16] H. B. Bai and X. Q. Huang, "An IHB method for the analysis of cubic nonlinear viscous damping and bilinear delayed vibration system," Journal of Xi'an Jiaotong University, vol. 32, pp. 35-38, 1998.

[17] F. L. Cao, H. B. Bai, D. W. Li, G. Ren, and G. Li, "A constitutive model of metal rubber for hysteresis characteristics based on a meso-mechanical method," Rare Metal Materials and Engineering, vol. 45, no. 1, pp. 1-6, 2016.

[18] T. Li, H. B. Bai, C. H. Lu, and F. Cao, "Constitutive models of knitted-dapped metal rubber based on microstructure characterization," Journal of Vibration and Shock, vol. 37, no. 12, pp. 75-82, 2018.

[19] A. M. Ulanov and Y. K. Ponomarev, "Finite element analysis of elastic-hysteretic systems with regard to damping," Russian Aeronautics (Iz VUZ), vol. 52, no. 3, pp. 264-270, 2009.

[20] D. Zhang, F. Scarpa, Y. Ma, J. Hong, and Y. Mahadik, "Dynamic mechanical behavior of nickel-based superalloy metal rubber," Materials \& Design (1980-2015), vol. 56, pp. 69-77, 2014. 
[21] Y. H. Ma, Q. C. Zhang, D. Y. Zhang, W. Hu, and J. Hong, "Experimental investigation on the dynamic mechanical properties of soft magnetic entangled metallic wire material," Smart Materials and Structures, vol. 26, no. 5, Article ID 055019, 2017.

[22] Q. Tan, P. Liu, C. Du, L. Wu, and G. He, "Mechanical behaviors of quasi-ordered entangled aluminum alloy wire material," Materials Science and Engineering: A, vol. 527, no. 1-2, pp. 38-44, 2009.

[23] L. Courtois, E. Maire, M. Perez, D. Rodney, O. Bouaziz, and Y. Brechet, "Mechanical properties of monofilament entangled materials," Advanced Engineering Materials, vol. 14, no. 12, pp. 1128-1133, 2012.

[24] K. Wu, H. Bai, X. Xue, T. Li, and M. Li, "Energy dissipation characteristics and dynamic modeling of the coated damping structure for metal rubber of bellows," Metals, vol. 8, no. 7, p. 562, 2018.

[25] M. Motezaker and A. Eyvazian, "Post-buckling analysis of Mindlin cut out-plate reinforced by FG-CNTs," Steel and Composite Structures, vol. 34, no. 2, pp. 289-297, 2020.

[26] M. Motezaker, M. Jamali, and R. Kolahchi, "Application of differential cubature method for nonlocal vibration, buckling and bending response of annular nanoplates integrated by piezoelectric layers based on surface-higher order nonlocalpiezoelasticity theory," Journal of Computational and Applied Mathematics, vol. 369, Article ID 112625, 2020.

[27] M. A. Msekh, N. H. Cuong, G. Zi, P. Areias, X. Zhuang, and T. Rabczuk, "Fracture properties prediction of clay/epoxy nanocomposites with interphase zones using a phase field model," Engineering Fracture Mechanics, vol. 188, pp. 287299, 2018.

[28] H. Talebi, M. Silani, S. P. A. Bordas, P. Kerfriden, and T. Rabczuk, "A computational library for multiscale modeling of material failure," Computational Mechanics, vol. 53, no. 5, pp. 1047-1071, 2014.

[29] K. Xiao, H. B. Bai, X. Xue, and Y. W. Wu, "Damping characteristics of metal rubber in the pipeline coating system," Shock and Vibration, vol. 2018, no. 11, Article ID 3974381, 2018.

[30] H. B. Bai, C. H. Lu, and F. L. Cao, Metal Rubber Material and Engineering Application, Science Press, Beijing, China, 2014.

[31] L. Cohen, Time-Frequency Analysis: Theory and Applications, Prentice-Hall, Inc., Upper Saddle River, NJ, USA, 1995.

[32] Y. Y. Wang, H. B. Bai, and Y. F. Liu, "Study on microscopic characteristics of compressive properties of metal rubber materials," Mechanical Science and Technology, vol. 30, pp. 404-407, 2011.

[33] J. Zhang, R. J. Perez, and E. J. Lavernia, "Documentation of damping capacity of metallic, ceramic and metal-matrix composite materials," Journal of Materials Science, vol. 28, no. 9, pp. 2395-2404, 1993. 